\title{
Juventudes en el movimiento Masortí argentino: percepciones sobre el Ethos comunitario*
}

\author{
[Versión en Castellano] \\ Youth in the Argentine Masorti Movement: Perceptions About the \\ Ethos Community
}

Juventude no movimento argentino Masortí: percepções sobre oethos comunitário

Recibido el 1 de febrero, 2019. Aceptado el 6 de marzo, 2020.

\author{
Vanesa-Cynthia Lerner** \\ https://orcid.org/0000-0002-4759-5844
}

Argentina

, Para citar este artículo:

Lerner, Vanesa-Cynthia (2021).

Juventudes en el movimiento

Masortí argentino: percepciones

sobre el ethos comunitario.

Ánfora, 28(50), 215-248.

https://doi.org/10.30854/anfv28.n50.2021.582

Universidad Autónoma de

Manizales. ISSN 0121-6538/

e-ISSN 2248-6941.

CC BY-NC-SA 4.0

\section{Resumen}

Objetivo: describir y comprender el modo de habitar o el ethos comunitario que tiene la juventud institucionalizada dentro del movimiento conservador Masortí en la ciudad Autónoma de Buenos Aires y analizar las tensiones de los y las jóvenes en su participación por fuera de los Departamentos de Juventud. Metodología: estudio cualitativo que se apoyó en el enfoque interpretativo. Se realizaron

\footnotetext{
* Este artículo forma parte de los resultados de la tesis de maestría "Construcciones identitarias de los jóvenes que participan en el movimiento conservador/masortí en la Ciudad Autónoma de Buenos Aires en la actualidad", en el marco del proyecto doctoral "El sentido de lo judío en el mundo del judaísmo. Religión, identidad y juventud en el movimiento conservador/masortí argentino en la Ciudad de Buenos Aires en la actualidad" financiado por El Consejo Nacional de Investigaciones Científicas y Técnicas (CONICET), 2015-2020. Algunos apartados se basaron en la presentación realizada en la VI Reunión Nacional de Investigadores/as en Juventudes de Argentina, Córdoba, Noviembre de 2018. La investigadora declara que no hubo conflicto de interés en la ejecución del proyecto de investigación.

** Magíster en Investigación en Ciencias Sociales. Doctoranda en Ciencias Sociales (Facultad de Ciencias Sociales-Universidad de Buenos Aires). Becaria Interna Doctoral del CIS-IDES/CONICET, Ciudad Autónoma de Buenos Aires, Argentina. Profesora de la Universidad de El Salvador. Correo: vanesalerner@gmail.com
} 
observaciones participantes en actividades del movimiento Masortí y entrevistas semi-estructuradas ajóvenesque participanenél. Resultados: seencontróque existen juventudes institucionalizadas en el movimiento Masortí que participan por medio de la educación no formal, dirigiendo sus actividades a niños, niñas y adolescentes. A partir de ese rol desarrollan un ethos comunitario que flaquea cuando deben terminar sus estudios universitarios o insertarse en el mercado laboral; estas obligaciones hacen imposible compatibilizar dicha participación al punto tal de abandonarla. Por otra parte, están las juventudes no institucionalizadas -estudiantes universitarios o terciarios, profesionales y/o comerciantes sin hijos- que no tienen espacios concretos ni radios de acción en el movimiento y circulan por otras organizaciones. El mundo adulto cuestiona esos modos de habitar por hacerlo de acuerdo a lógicas utilitarias alejándose de la idea de ethos. Conclusiones: se concluye que es la condición de joven la que garantiza la participación en el movimiento y la reproducción de ese ethos. Por su parte, el movimiento Masortí ofrece espacios de socialización para una juventud institucionalizada y para las familias. La juventud institucionalizada habita lo comunitario por medio de un rol específico en pos de una empresa a largo plazo.

Palabras-clave: Juventudes judaístas; Identidad judía; Movimiento Masortí argentino; Ethos Judio-comunitario.

\section{Abstract}

Objective: to describe and understand the way of living or the community ethos of the youth organization within the conservative Masortí movement in the Autonomous city of Buenos Aires and analyze the tensions of young people in their participation outside the Youth Departments. Methodology: a qualitative study that was based on the interpretative approach. Participant observations were made in activities of the Masortí movement and semi-structured interviews were held with young people who participated in it. Results: it was found that there are institutionalized youths in the Masortí movement who participate through non-formal education, directing their activities towards children and adolescents. From this role they develop a community ethos that falters when they must finish their university studies or enter the labor market. These obligations make it impossible to make such participation compatible to the point of abandoning it. On the other hand, there are the non-institutionalized youths - university or tertiary students, professionals and / or merchants without children - who do not have specific spaces or operating ranges in the movement and circulate through other organizations. The adult world questions these ways of living by following utilitarian logic, moving away from the idea of ethos. Conclusions: it is concluded that it is the condition of youth that guarantees participation in the 
movement and the reproduction of that ethos. For its part, the Masortí movement offers socialization spaces for institutionalized youth and families. Institutionalized youth inhabit the community through a specific role in pursuit of a long-term company.

Keywords: Jewish youth; Jewish identity; Argentine Masortí Movement; Ethos Jewish-community.

\section{Resumo}

Objetivo: descrever e entender o modo de vida ou o ethos comunitário que os jovens institucionalizados possuem no movimento conservador Masortí, na cidade autônoma de Buenos Aires, e analisar as tensões dos jovens em sua participação fora dos Departamentos da Juventude. Metodologia: estudo qualitativo, baseado na abordagem interpretativa. As observações dos participantes foram feitas em atividades do movimento Masortí e entrevistas semiestruturadas com jovens que participam dele. Resultados: verificou-se que existem jovens institucionalizados no movimento Masortí que participam da educação não formal, direcionando suas atividades para crianças e adolescentes. A partir desse papel, eles desenvolvem um ethos comunitário que oscila quando devem terminar os estudos universitários ou entrar no mercado de trabalho; Essas obrigações tornam impossível fazer essa participação compatível a ponto de abandoná-la. Por outro lado, existem jovens não institucionalizados - estudantes universitários ou terciários, profissionais e / ou comerciantes sem filhos - que não possuem espaços ou rádios de ação específicos no movimento e circulam por outras organizações. O mundo adulto questiona esses modos de vida, fazendo-o de acordo com a lógica utilitarista, afastando-se da idéia de ethos. Conclusões: conclui-se que é a condição da juventude que garante a participação no movimento e a reprodução desse ethos. Por seu lado, o movimento Masortí oferece espaços de socialização para jovens institucionalizados e famílias. Os jovens institucionalizados habitam a comunidade através de um papel específico na busca de uma empresa de longo prazo.

Palavras-chave: Juventude judaista; Identidade judaica; Movimento Masortí argentino; Comunidade judaica Ethos. 


\section{Introducción}

El movimiento conservador Masortí argentino está compuesto por una red de organizaciones que pueden ser sinagogas o sinagogas-escuelas que las y los actores llaman "comunidades"; catorce de ellas cuentan con Departamentos de Juventud y están adheridas a Noam Argentina. En ellos, los y las jóvenes madrijim/madrijot -en hebreo, líderes o guías- brindan educación no formal a niños y adolescentes entre 3 y 16 años. Noam Argentina forma parte de Noam Olami, organización mundial encargada de promover educación no formal a nivel mundial a niños y adolescentes entre 8 y 18 años. Su sede central está en los Estados Unidos, con filiales en diferentes países.

En el caso argentino, el movimiento conservador/masortí en 2017 registró 37 "comunidades", número significativo en comparación con otros países. En 2020 existen 14 comunidades con Departamentos de Juventud que forman parte de Noam (Amijai, Bet-El, BetHilel, BeneiTikvá, Beit Israel, Bialik de Devoto, OrJadash, DorJadash, Comunidad Pardés, Lamroth ha Kol, Sio de Morón, Tfilat Shalom, Juventud Judaica y Ioná). Todas ellas están ubicadas en la Ciudad Autónoma de Buenos Aires y en el Gran Buenos Aires.

Aunque en el interior del país existen "comunidades" y organizaciones juveniles cuya espiritualidad es conservadora/masortí, no se encuentran adheridas a Noam sino a los movimientos juveniles sionistas. Dentro del mundo juvenil judío existe una amplia oferta vinculada con la educación no formal que varía de acuerdo con sus posicionamientos ideológicos, religiosos o laicos. Ejemplos de ellas son: las entidades sociodeportivas adheridas a la Federación Argentina de Centros Comunitarios Macabeos (FACCMA), las asociadas al Movimiento Juvenil Sionista y al Idisher Cultur Farband (ICUF). Asimismo, se encuentra la Fundación Bamá (Beit Hamejanej Haiehudí -La casa del Educador Judío), quien también promueve la educación tanto formal como no formal en las organizaciones judeo-argentinas.

Por lo anterior, este artículo tiene como objetivo describir y comprender el modo de habitar o el ethos comunitario que tiene la juventud institucionalizada dentro del movimiento conservador/masortí en la ciudad Autónoma de Buenos Aires. También busca analizar las tensiones que aparecen en los y las jóvenes que participan por fuera de los Departamentos de Juventud y, a su vez, exponer algunas percepciones del mundo adulto del movimiento al reflexionar sobre otras juventudes que no participan a partir de un trabajo voluntario.

Ahora bien, Max Weber (1979) entiende al ethos en tanto ética como una dimensión actitudinal, un conjunto de valores y motivaciones que remite a las cualidades morales del individuo. En cuanto a lo comunitario, se trata de un espacio de socialización en el que todos se conocen y quienes participan lo hacen 
de acuerdo con una "acción racional con arreglo a valores" que está "determinada por la creencia consciente en el valor -ético, estético, religioso o de cualquiera otra forma como se la interprete- propio y absoluto de una determinada conducta, sin relación alguna con el resultado, o sea puramente en méritos de ese valor" (Weber, 1964, p. 20).

Retomando lo planteado por Zygmunt Bauman (2008) la comunidad posmoderna evoca significados relacionado con lo bueno, lo cálido y apacible. Es una comunidad imaginada que retoma las características de aquella descrita por Ferdinand Tönnies (1979) y por Robert Redfield (1971) -la existencia un entendimiento compartido "tácito" y "natural", por ser pequeña, distintiva y autosuficiente-, pero que en realidad ya no existe pues cae cuando se la hace autoconsciente, se la nombra, se la pregona y critica. Por el contrario, a pesar de no lograr establecer una frontera tajante entre un "nosotros" y un "otros", mantener el monopolio de la comunicación y permanecer aislada del mundo externo, opera como si esto efectivamente sucediera.

Dicho modo de habitar o ethos comunitario de la juventud institucionalizada fue desagregado en distintas dimensiones (el significado que tiene para ella asumir ese rol de educador no formal, la estructura organizacional y la forma de trabajo, el contenido pedagógico, el ethos y los valores a transmitir y sus motivaciones por participar de ese modo) para luego, en una segunda parte, desarrollar los objetivos subsiguientes relacionados con las juventudes y las tensiones con el mundo adulto.

La identidad judía contiene una diversidad de dimensiones (ideológicas, religiosas, culturales, étnicas, nacionales, políticas, lingüísticas, idiomáticas y geográficas), que redefinidas desde la significación particular de cada sujeto, otorgan al judaísmo una representación multifacética (Erdei, 2011; Caro, 2006; Baumann, 2001). Lo religioso constituye así una de ellas que comprende a las identificaciones con lo judío, cuyo peso es significativo.

Los actores sociales en términos generales sostienen la existencia de tres corrientes: la ortodoxa, la reformista y la conservadora/masortí. La primera, cumple con la Ley Judía (en hebreo halajá) y se caracteriza por la observancia rigurosa de los preceptos religiosos, mientras que la segunda la deja de lado y apela a la autonomía individual (Kepel, 1995). La conservadora/masortí se definió a sí misma como una tercera posición entre las otras dos ya que "conservaba" el cumplimiento de la Ley Judía al igual que la primera pero adaptándola a las necesidades de la feligresía, cuyo estilo de vida es secular y está inmersa en una sociedad no judía como la segunda. Cumple con el Shabat (Sábado) permitiendo que la feligresía llegue a la sinagoga utilizando algún medio de transporte y, por lo tanto, tocando dinero, el uso de instrumentos musicales y micrófonos en las 
ceremonias, la incorporación del idioma vernáculo en el recitado de plegarias, todas cuestiones que la ortodoxia prohíbe.

También incluye la circuncisión, los rezos diarios, el precepto del matrimonio, el divorcio, la conversión de acuerdo con la Ley Judía, el uso del hebreo en los servicios religiosos y la centralidad espiritual de la Tierra de Israel y de su Pueblo. Introdujo el concepto de Klal Israel de Zacarías Frankel, cuya traducción es "El conjunto de Israel" haciendo referencia a una pertenencia de carácter nacional (Waxman, 1970; Cohen, 1987). Asimismo, a diferencia de la ortodoxia, cambió el status de las mujeres habilitándolas a compartir el mismo espacio con los hombres en la sinagoga, conformar minian (quórum mínimo de diez personas para los rezos), leer la Torá (Pentateuco) en público y ocupar cargos rabínicos.

Sin embargo, no alcanzarían a obtener las mismas condiciones de igualdad que los hombres (Sklare, 1972). También se la conoce como masortí, que en hebreo significa tradicionalista. Para el caso puntual de la feligresía conservadora/ masortí de Argentina, la misma tiene naturalizada que lo religioso se recrea al ingresar a la "comunidad" y no necesariamente fuera de ella. Esto no es así en otras partes del mundo.

El movimiento conservador/Masortí se originó en Europa Occidental a mediados del siglo XIX, tras los avances del Iluminismo y la constitución de los Estados-Nación, en ese entonces conocido como corriente judeo-histórica positiva. Con las leyes emancipadoras, los judíos adquirieron el status de ciudadanos lo que implicó cambios y tensiones en la organización sociopolítica de las comunidades religiosas pues hasta el momento, sus autoridades eran las que ejercían el poder político y legal en los guetos independientemente de las autoridades centrales (Meyer, 1995). La obtención de derechos políticos dio lugar a un proceso de confesionalización que relegó la judeidad a la esfera privada (Traverso, 2013).

$\mathrm{Su}$ institucionalización se dio en los Estados Unidos a fines XIX siendo el Jewish Theological Seminary of America el referente académico e ideológico. En el caso argentino, éste se estableció en 1957 cuando la Congregación Israelita de la República Argentina (CIRA), que adhería a la corriente reformista europea, decidió unirse a la United Synagoges of America. De modo que, en 1959, el rabino conservador estadounidense Marshall T. Meyer, egresado de Jewish Theological Seminary, llegó a dicho país para hacerse cargo de la organización, convirtiéndose en el principal referente del movimiento (Schenquer, 2012).

De igual modo, el reformismo estadounidense se instaló en Argentina junto con el movimiento conservador/masortí en la década de 1960. El rabino búlgaro Haim Asa quien adhería al reformismo estadounidense vino de los Estados Unidos a Buenos Aires en 1963 y conformó la Comunidad Emanu El en 1965. De todos modos, para el caso argentino, las diferencias entre dichas corrientes no fueron tan tajantes. La formación de rabinos de ambas pasaba por 
el Seminario Rabínico Latinoamericano dirigido por los rabinos Marshall Meyer y Mordejai Edery.

El movimiento conservador/masortí fue hegemónico en la región latinoamericana ante el reformismo. "Comunidades" que adherían al reformismo europeo, judeolaicas o que desarrollaban una ortodoxia moderada definida como "tradicionalista" comenzaron a afiliarse al movimiento conservador/masortí entre las décadas de 1970 y 1980 (Schenquer, 2012). Ello implicaba la contratación de un rabino o seminarista formado en el Seminario. En cuanto a la ortodoxia, existen distintos tipos y vertientes. Algunas que llegaron a la Argentina con los procesos migratorios de fines del siglo XIX y otras que se fueron radicando en el país bajo la misma lógica que el movimiento conservador/masortí o el reformismo.

El reclutamiento de rabinos de diferentes partes del mundo para hacerse cargo de distintas congregaciones no fue exclusivo de estos movimientos. Siguiendo a Susana Bianchi (2004) hacia la década de 1960, dentro del mundo judío se reconocía una crisis dentro del campo religioso. "La sinagogas parecían estar vacías y su número no crecía” (p. 252). Esto se debía al estancamiento de nuevas olas inmigratorias y según las dirigencias comunitarias, debido a un alejamiento de la feligresía de las prácticas rituales con un estilo de vida secularizado.

La contratación de rabinos del exterior implicaba para las dirigencias revitalizar lo religioso, aunar criterios sobre los rituales "realizados muchas veces inescrupulosamente". Por ejemplo, el rabino Isaac Chehebar oriundo de Alepo fue designado en 1953 como el especialista religioso de la escuela sefaradí de origen alepino Yesod Hadath para restaurar la autoridad rabínica y el cumplimiento de los preceptos judaicos. El rabino Dov Ber Baumgarten radicado en los Estados Unidos, discípulo del Rebe-Menahem Mendel Schneerson, viajó en 1956 a Argentina como el primer emisario de la corriente jasídica Jabad Lubavitch en dicho país. Asímismo, el rabino alemán Iosef Oppenheimer proveniente de Holanda en 1953 fue contratado para dirigir la Congregación Ajdut Israel en Buenos Aires, sinagoga ortodoxa de origen alemán en reemplazo del rabino Hermann Klein quien era muy anciano.

Si bien dentro del movimiento conservador/masortí existen organizaciones centrales (como la anteriormente nombrada, la Asamblea Rabínica, la Comisión de Ley Judía y Estándares que por votación puede crear responsas nuevas, la Asamblea Rabínica Latinoamericana, el Seminario Rabínico Latinoamericano, etc.) que lo ordenan y bajan los principales lineamientos, el mismo funciona de forma descentralizada. Esto es así ya que la figura rabínica en sus respectivas "comunidades" posee la autoridad máxima (mara d'atra) en cuanto lo religioso. Puede decidir sobre el cumplimiento de los preceptos y la forma de aplicarlos, pero no puede inventar responsas nuevas. No obstante, en la práctica se da un doble poder. 
Las "comunidades" son organizaciones civiles sin fines de lucro gobernadas por Comisiones Directivas conformadas por familias fundadoras o de peso. La aplicación de la Ley Judía es producto de una negociación entre la figura rabínica que detenta el poder religioso con las Comisiones Directivas encargadas de administrar los recursos económicos. Las fronteras entre el poder religioso y económico son poco claras para definir lo sagrado y lo profano. A la vez, existe una historia institucional en cuanto a la aplicación de la Ley Judía que trasciende a la figura religiosa. Es decir, que dentro del movimiento hay comunitarismos (Hervieu-Léger, 2004; Giménez-Béliveau, 2016).

Existe un amplio espectro dentro de lo masortí que va estar condicionado por las anteriores cuestiones. Esto puede verse en el rol de la mujer y los grupos LGBTIQ. En las "comunidades" de Buenos Aires, las mujeres ocupan cargos directivos, ejercen voluntariados, trabajan como cantantes litúrgicas y pueden desempeñarse como rabinas. De los 105 rabinos graduados del Seminario Rabínico Latinoamericano registrados en su página web entre los años 1972-2018 ${ }^{1}$, 11 son mujeres siendo la primera, la rabina Margit Baumatz egresada en 1994 con 56 años casada y con tres hijas adultas. Siete viven en Buenos Aires y cuatro en Brasil, Estados Unidos e Israel.

Por lo general, a las mujeres les resulta dificultoso insertarse en las "comunidades" como única autoridad máxima. En sus trayectorias pueden notarse que han compartido ese lugar con rabinos hombres, que han estado al mando solas por un tiempo limitado o que se dedican a la docencia y en menor medida al púlpito. Ellas cuentan que las Comisiones Directivas prefieren liderazgos masculinos por sobre los femeninos. Es decir, que para las mismas, el liderazgo comunitario resulta ser un campo de disputa.

En 2020 solo hay una "comunidad" en la Ciudad de Buenos Aires exclusivamente a cargo de una rabina mujer y otra con conducción compartida. En cuanto a los grupos LGBTIQ, la Comisión de Ley Judía y Estándares (Committee on Jewish Law and Standards) ubicada en los Estados Unidos aprobó el 6 de diciembre de 2006 la responsa "Homosexuality, Human Dignity Eं Halakhah: a combined responsum for the Committee on Jewish Law and Standards" que permite la ordenación de rabinas y rabinos homosexuales y el matrimonio entre personas del mismo sexo. Sin embargo, como se explicó anteriormente cada "comunidad" resuelve. Rabinos o rabinas pueden estar a favor de desarrollar el ritual del casamiento pero solo lo podrán ejecutar estableciendo consensos con las Comisiones Directivas. Ejemplo de ello fue el casamiento llevado a cabo por la rabina Karina

\footnotetext{
1. Información obtenida en el curso curso abierto llamado "Judaísmo conservador/masortí" dictado una vez por semana en el Seminario Rabínico Latinoamericano "Marshall T. Meyer" ubicado en la Ciudad Autónoma de Buenos Aires entre agosto y diciembre de 2011 corroborada en la página web del Seminario Rabínico Latinoamericano: https://www.seminariorabinico.org/graduados/rabinos-graduados/.
} 
Finkielsztein en la Comunidad NCI-Emanuel en 2016 quien unió en matrimonio a dos mujeres, Romina Charur y Victoria Escobar.

Dicha comunidad pertenece a Fundación Judaica, un entramado institucional de doble afiliación (conservadora y reformista) dirigido por el rabino Sergio Bergman. JAG (Judíos Argentinos Gays) forma parte de dicho entramado desde 2008 luego de la fusión de JAG y de Keshet. Ambas se conformaron en 2004, la primera se proponía generar espacios de socialización puertas hacia adentro y la segunda buscaba visibilizar la cuestión judeo-gay hacia el adentro judío y hacia el afuera no judío. Si bien comenzaron siendo espacios en los que participaban hombres gays, luego se incorporaron mujeres, entre ellas Romina y Victoria (Setton, 2015, 2020).

Durante el trabajo de campo, diferentes rabinos y rabinas se pronunciaron a favor del matrimonio igualitario, otros en contra. Todos coincidían que en caso de llevarlo a cabo debían consultarlo con su "comunidad". Las y los actores que participan en JAG buscan que las "comunidades" tengan políticas inclusivas para los participantes ${ }^{2}$. Aunque con esta organización se visibilizó y se institucionalizó las demandas de inclusión, no tiene presencia en todas las comunidades. De las siete "comunidades" relevadas, sus figuras rabínicas formaron familias bajo la lógica heteronormativa.

Las transformaciones socioestructurales en los años 1990 en Argentina, junto con los procesos de globalización, impactaron en el movimiento conservador/masortí tanto en términos materiales como en términos simbólicos. El atentado terrorista a la Asociación Mutual Israelita Argentina (AMIA) en 1994 y la quiebra de los bancos judíos Patricios y Mayo impactó económicamente en las organizaciones adheridas al movimiento conservador/ masortí. A su vez, muchas de ellas no pudieron adaptarse a los cambios culturales de la época de modo que cerraron (Rubel, 2011).

Si bien tal como ya se ha planteado, la identidad judía es diversa, con los procesos de globalización se hizo presente una variedad de formas de identificación con lo judío, desafiando dichos límites. Las afiliaciones religiosas y educativas conservadoras/masortí comenzaron a competir con otras ofertas religiosas dentro del campo judío.

Por un lado, se cuestionaron aquellos patrones de cómo vivir el judaísmo asociado a las afiliaciones comunitarias estableciéndose nuevas modalidades de "cultura judía off" o "Light" en la que cada individuo decide cómo llevar a la práctica el judaísmo. Aparecieron nuevas formas de cultura mercantil como

2. Sobre la construcción de identidades judeo-gay, ver los trabajos de Cooper (1989), Setton (2014), Gómez (2017).

3. Daniel Fainstein $(1994 ; 15)$ explica que se trata de una corriente que "define el ser judío como un sentimiento difuso, un sentido de cierta pertenencia "light", que no implica ni lenguajes ni códigos 
festivales de cine judío, bares y restaurantes de cocina judía en el barrio de Palermo, empresas de turismo que promocionan "City Tour Buenos Aires Judía", celebraciones a cielo abierto ${ }^{4}$, etc. (Hupert, 2014). Por el otro, se dio una fuerte secularización y paralelamente una revitalización de la ortodoxia (Aviad, 1983; Topel, 2005; Brauner, 2009; Setton, 2010).

Nuevos movimientos trasnacionales ultraortodoxos desplegaron un anclaje de pertenencia y orden social capaz de generar nichos de certeza (Setton, 2008). Con la crisis de 2001, dichas organizaciones ultraortodoxas no se vieron afectadas logrando conformar una red educativa y comunitaria autónoma sumamente involucrada con las problemáticas locales (Melamed, 2000) y empezaron a constituirse como centros de legitimidad estableciéndose una lucha simbólica de cómo pensar al judaísmo. Además, se evidenciaron cambios en la relación centro-diáspora, estableciéndose disensos en torno al Estado de Israel como catalizador central de la identificación judía (Senkman, 2007; Bokser-Liwerant, 2011; Della-Pergola, 2011; Kacowicz, 2011). Por lo tanto, se puede observar cómo las fronteras identitarias se hacen difusas y cambiantes, pues los actores comienzan a circular sucesiva y simultáneamente (Mallimaci y Giménez-Béliveau, 2007). Otros autores y autoras han realizado investigaciones sobre el origen del movimiento conservador/masortí focalizándose en el liderazgo de Marshall Meyer y su vínculo con los jóvenes (Weil, 1988; Weiss, 1988; Fainstein, 2006; Rosemberg, 2010; Schenquer, 2012) o han reflexionado acerca de su crisis tras las transformaciones de la posmodernidad (Laikin-Elkin, 1986), poco se ha escrito sobre las maneras en que estas transformaciones institucionales afectaron a los y las jóvenes que adhieren a dicho movimiento tratándose de un actor central para el mismo.

Teniendo en cuenta la presencia de la juventud en los procesos de transformación identitaria dentro del colectivo social judío por medio de diferentes movimientos y organizaciones (Caro, 2006) vale preguntarse, ¿qué ha ocurrido con los jóvenes que adhieren al movimiento conservador/masortí argentino en sus procesos de construcción identitaria en la actualidad? ¿Cómo se definen a sí mismos y fijan límites con "otros"? ¿Las instituciones masortí perdieron ese carácter organizador y regulador? o ahora ¿ilos y las jóvenes judíos deben pensar lo religioso por fuera de ellas?

específicos, ni conductas particulares ni compromisos colectivos. Según esta postura ser judío "es un sentimiento" que no requiere de acciones determinadas, sino simplemente de la apropiación subjetiva de una condición de origen dada".

4. Ejemplo de ellos es el "Rosh Ha Shana Urbano". Por la celebración del año nuevo judío, se lleva a cabo en el barrio de Belgrano en la Ciudad Autónoma de Buenos Aires un evento al aire libre con ofertas gastronómicas judías, espectáculos de música, danza, teatro, etc. 
Indagar esta cuestión no solo implicaría un aporte para el campo de la Sociología de la Religión pudiendo dialogar con investigaciones que abordaron lo juvenil (Romero-Ocampo, 2010; Mosqueira, 2014; Barrón, 2018; Fernández, 2018; Lago, 2018), sino también una contribución para los estudios sobre juventud ya que esta investigación de igual forma recupera lo juvenil entendiéndolo como constructo histórico, social, cultural y relacional (Bourdieu, 1990). Este estudio también cobra sentido contextualmente al interior de relaciones de poder y en interacción con categorías extra-juveniles como las de clase social, género, etnia, entre otras. En ese sentido, la juventud no debe ser pensada como un grupo social continuo y ahistórico, sino dinámico y discontinuo, donde los y las jóvenes constituyen una categoría heterogénea, tanto diacrónica como sincrónicamente. No se puede hablar de un tipo de juventud sino de juventudes (Reguillo-Cruz, $2000)^{5}$.

\section{Metodología}

Esta investigación cualitativa se valió del enfoque interpretativo como perspectiva conceptual dentro de la investigación sociológica centrándose primariamente en los aspectos simbólicos de la vida social y en los significados de la vida individual (Sautú, 1999). En el mundo de la interpretación subjetiva del sentido, se considera importante la comprensión de la acción social como sentido que el actor asigna a su acción (Schutz, 1974).

Para construir el objeto de estudio, la juventud masortí, el trabajo de campo se realizó en tres etapas. En primer lugar, se llevó a cabo observaciones participantes de un curso abierto llamado "Judaísmo conservador/masortî" dictado una vez por semana en el Seminario Rabínico Latinoamericano "Marshall T. Meyer", ubicado en la Ciudad Autónoma de Buenos Aires entre agosto y diciembre de 2011 . Estuvo dirigido al público en general interesado y a alumnos y alumnas del Seminario que aspiraban a ser rabinos, seminaristas, cantores y docentes o aquellos que estaban en un proceso de conversión al judaísmo. En él, algunos rabinos y rabinas dieron clases sobre un tema en particular en los que eran especialistas, por ejemplo: la historia del movimiento, las organizaciones que lo componen o posicionamientos halálijos sobre rabinos gays, rabinato femenino, matrimonio igualitario, conversión al judaísmo, etc.

Este acercamiento permitió obtener una mirada general respecto del movimiento: sus principales premisas, dilemas, cuestionamientos, sus definiciones

5. Diferentes autores han abordado lo juvenil desde esta perspectiva relacional, heterogénea, histórica. Ejemplos de ellos son: Mekler (1992), Feixa (1998), Pérez-Islas (2000), Wortman (2001), Margulis y Urresti (2008), Alvarado y Vommaro (2010), Chaves (2010), Kriger (2016), entre otros. 
de sí mismos y de los "otros". Con el consentimiento de los rabinos y rabinas docentes se grabaron las clases y se tomaron notas de campo de las mismas así como también de las charlas informales con compañeros y compañeras. Tanto en este caso como en las etapas siguientes, se informó sobre los objetivos, los propósitos de la investigación y la identidad de la investigadora. El hecho de tener una participación dentro del movimiento hizo más fácil el acceso.

En segundo lugar, entre junio y diciembre de 2013 se hizo observaciones en un espacio religioso y cultural de una organización conservadora/masortí dirigido a jóvenes entre 25 a 35 años. Se contó con notas de campo de rituales, clases y charlas informales. Esta experiencia permitió comprender qué tipo de ofertas existe para los y las jóvenes que deciden participar en el movimiento por fuera de los Departamentos de Juventud ejerciendo la educación no formal. Lamentablemente cuando en una segunda etapa se buscó pautar encuentros para la realización de entrevistas con los actores, el espacio se había desintegrado. Reconocer que se trataba de un espacio efímero y sin continuidad permitió dar cuenta de las dificultades que existen en los y las jóvenes en seguir participando en el movimiento sin ejercer la educación no formal. Eran personas que estaban estudiando en la universidad o haciendo una carrera terciaria o profesionales y/ o comerciantes. Trabajaban jornadas completas, lograron una independencia económica o estaban en ese proceso, vivían solos y no eran padres.

Definitivamente, si el objeto de interés era el joven, se lo debía encontrar en los espacios juveniles institucionalizados por el movimiento evidenciando su especificidad, quien participa, lo hace en un determinado momento de su vida y tiene una trayectoria particular. A la vez, la estabilidad del espacio facilitaría la entrada y la salida las veces que sea necesario teniendo en cuenta que se trata de una investigación a largo plazo. Al mismo tiempo esa información obtenida permitiría dialogar con la experiencia anterior.

De este modo, en la tercera etapa de trabajo de campo se realizaron entre febrero de 2016 y septiembre de 2017, 32 entrevistas semi-estructuradas a jóvenes de cinco "comunidades" que participan dentro de la educación no formal. Aparte, ya se contaba con una entrevista aplicada en abril de 2011 al secretario de Noam, observaciones participantes de cursos, congresos, actividades dirigidas a jóvenes, ceremonias religiosas entre 2013 y 2017.

También se tomó como unidad de análisis a los y las jóvenes que participan como educadoras no formales en los distintos Departamentos de Juventud delas "comunidades" que adhieren al movimiento conservador/masortí y están asociadas a la organización Noam Argentina ubicados en la Ciudad Autónoma de Buenos Aires. Dicha técnica de recolección de datos permitió recuperar la voz de los actores e indagar en sus representaciones y relatos biográficos tratando de buscar flexibilidad sin dejar de desarrollar las ideas de la investigadora (Denscombe, 1999). Asimismo, se hicieron observaciones en una "comunidad" 
en particular entre noviembre y diciembre de 2016 y marzo de 2017. La guía de observación estuvo compuesta por los siguientes puntos: dinámica de trabajo (grupal, individual); uso del espacio; temas que se abordaban en la reunión; vínculos interpersonales entre los y las jóvenes y duración de los encuentros. Todos los nombres de las organizaciones y de los entrevistados son ficticios para preservar su identidad de manera que, cualquier nombre que tenga similitud con la realidad es pura coincidencia.

Tratándose de una investigación que no buscó representatividad estadística, el muestreo se basó en criterios de tipo teórico través de la técnica "Bola de nieve". Los ejes de indagación fueron: trayectorias, interacciones y circuitos dentro del movimiento masortí; las representaciones de los y las jóvenes sobre Israel y el conflicto de Medio Oriente, la Shoá, las fechas patrias y temas de actualidad argentina, la transmisión del contenido judío (relatos bíblicos, símbolos y costumbres) y valores en sus actividades; $y$, los sentidos de pertenencia sobre el movimiento masortí. A diferencia de la juventud anterior, eran jóvenes que estaban terminando sus estudios secundarios o iniciando sus estudios universitarios. Trabajaban pocas horas o no trabajaban, tenían sus pasatiempos y en su mayoría vivían con sus padres que por lo general eran profesionales y/o comerciantes. A partir de la información obtenida se hizo un análisis temático recuperando conceptos sensibilizadores, entre ellos el de ethos o habitar comunitario.

\section{Resultados}

\section{Significado de ser madrij, un emprendedor de una moral masortí}

A los y las jóvenes se los llamó emprendedores de una moral masortí, concepto tomado de Howard Becker (2014). A partir de sus actividades, de su hacer, ponen en práctica 'iniciativas morales', que incluyen leyes, valores y reglas ${ }^{6}$, mostrando qué es lo correcto y lo incorrecto de acuerdo con el código masortí. Esta categoría incluye a los secretarios y secretarias o en hebreo mazkirim/mazkirot a cargo de la dirección de Noam así como a los diferentes escalafones que conforman los Departamentos de Juventud: los directores y directoras, los y las representantes del “Área de Juventud” ante las Comisiones Directivas, los coordi-

\footnotetext{
6. La autora hace esta clasificación teniendo como referencia el grado de ambigüedad. Asume que los valores son una guía vaga que orienta la acción general sin determinaciones concretas. Por el contrario las leyes son normas que explicitan con certeza qué se debe hacer y qué no. Las reglas son costumbres de un grupo que indican cómo actuar con mayor precisión aunque habilitando un amplio espectro de interpretaciones.
} 
nadores y las coordinadoras a cargo de las áreas divididas en Jardín de Infantes, Primaria y Secundaria, el coordinador o coordinadora educativo/a o en hebreo roshïnuj, el director o directora y el profesor o profesora del "curso de madrijim" y los madrijim y madrijot o los líderes y lideresas encargados de desarrollar las actividades para sus janijim/janijot o educandos y educandas (Freire, 2005) los días sábados. Tanto los educandos y educandas como los voluntarios, voluntarias, los rabinos, las rabinas, los cantores, cantoras y seminaristas quedaron por fuera de la categoría de emprendedores. Solo se contó a aquellos voluntarios que trabajan dentro de los Departamentos de Juventud. La decisión no solo tuvo que ver con su rol específico sino también con una cuestión generacional (Mannheim, 1990).

Howard Becker (2014) entiende que este tipo de emprendedor moral que aplica las leyes la fuerza policial de una cruzada moral. Se encarga de que ésta se cumpla. En teoría no le importa tanto el contenido de la norma sino hacerla cumplir, aunque a la vez aclara que en la práctica existen tensiones o conflictos entre los creadores de normas y los que las hacen cumplir. Tanto el emprendedor como cualquiera que tenga una ocupación (profesional, de oficio, etc.) tiene dos intereses que condicionan su labor: debe justificar la existencia de su cargo y ganarse el respeto de aquellos con quienes tiene que relacionarse.

Para el primer punto, si bien este emprendedor o emprendedora masortí se manifiesta en la esfera pública para evidenciar hechos injustos a través de la participación en actos de conmemoración por los atentados a la AMIA (1994) y a la Embajada de Israel (1992), la Shoá, etc., sus energías están puestas en generar y "enmarcar" conductas desviadas al interior de la "comunidad". Ejemplo de ellas son: el bullying, la indiferencia por el judaísmo o por aquél que necesita ayuda, la discriminación, etc. El acento está puesto en promover, empujar y dirigir energías en los niños y adolescentes que participan en ella. Mostrarles un "camino de bien” y ofrecerles un marco "sano” y de contención que los aleje de los peligros del "afuera”. Magali, joven de 25 años, explica que su función es vital, altruista, focalizada en dar un marco a cada vez más gente, lo que se traduce en el éxito de la organización y la perpetuación del espacio.

"Nosotros lo que tratamos de hacer es de dar un marco, una contención. Para los janijim tratamos de buscarle un marco dentro de todo sano, divertido y de pertenencia. En este año se sumaron muchos chicos que son nuevos que no conocían a nadie y que está buenísimo porque se les da un lugar donde ir un sábado a la tarde” (Entrevista a Magali, directora del Departamento de Juventud de Comunidad Menorá, 16 de septiembre de 2016). 
Para el segundo punto, los y las jóvenes dan cuenta de la existencia de una trayectoria o una "carrera" que los lleva a ejercer este rol de educador no formal. Primero se empieza como educando o janij. Las y los emprendedores cuentan que comenzaron a participar como educandos de pequeños o en su temprana adolescencia. Se asiste a las actividades y se participa de las propuestas pedagógicas que ofrecen el madrij o madrijá encargados de transmitir a sus educandos valores de convivencia, respeto, contenidos judaicos, costumbres.

Para poder ser educador es necesario hacer un curso de formación. Al igual que las figuras rabínicas, los madrijim y madrijot, una vez egresados de estos cursos, pasan a ser considerados especialistas (Bourdieu, 2006). Luego de adquirir experiencia, las "comunidades" recomendarán a aquellos líderes que estén en condiciones de ser coordinadores para hacer el "Curso de Nofim" en el Seminario Rabínico Latinoamericano. Después de ejercer como tales podrán aplicar al puesto de director.

En la definición que las y los emprendedores hacen de sí mismos explican que son personas que por medio de la educación no formal, son los encargados de transmitir saberes del judaísmo que incluye valores, costumbres y leyes pero a partir de diferentes recursos, entre ellos los lúdicos. Según sus testimonios, tienen claro su responsabilidad y diferencias con la educación formal, incluyendo la cercanía-distancia que tienen con sus educandos. Encuentran en ese rol un fuerte potencial en su práctica cotidiana pero también en un nivel más amplio. Dan cuenta que forman parte de una 'red de confianza' cuya praxis se encuadra en una empresa a largo plazo (Tilly, 2010) siendo un cuadro medio que acerca a niños, niñas y adolescentes al judaísmo:

"Se trata de un trabajo voluntario y generalmente yo considero que ser madrijá es mi forma de aportar el granito de arena a la comunidad, a la colectividad. Es una persona que aprende y transmite los valores y la historia judía” (Entrevista a Natalia, madrijá y coordinadora de Comunidad Tefilá, 18 años, 10 de abril de $2017)$.

"Es un educador que busca transmitirles ciertos conocimientos a los chicos pero no formalmente, sentados en un banco sino que a través de actividades recreativas y que los chicos se diviertan y a la vez aprendan. Pero ser también su consejero si lo necesita. Es un poco más cercano que un maestro pero no es un amigo" (Entrevista a Gabriela, madrijá de Comunidad Tefilá, 17 años, 22 de marzo de 2017). 


\section{Estructura organizacional y forma de trabajo}

Cada "comunidad" masortí tiene un Departamento de Juventud, cuya estructura organizacional es la siguiente: en la cúspide se encuentra la Dirección que tiene un vínculo directo con el director espiritual ya sea rabino, rabina o seminarista. Entre ambos deciden los grandes temas a desarrollar. Existe una Representación del Departamento de Juventud, habitualmente alguien con experiencia, que participa en las reuniones con la Comisión Directiva para discutir asuntos administrativos y presupuestarios. Luego, está la Coordinación dividida en tres áreas: Jardín de Infantes, Primaria y Secundaria, ésta en conversación con la Dirección, son las responsables de armar los proyectos educativos generales y por área ya sea a principio de año o sobre la marcha. En la medida en que están resueltos, se los comunican a los madrijim y a las madrijot quienes están a cargo de un grupo que se dividen por edades. Los niños y niñas de 3,4 y 5 años conforman el área de "Jardín", los chicos y chicas de primero a sexto grado están en el área "Primaria" y los de séptimo grado hasta 16 años en el área de "Secundaria". De acuerdo con el tamaño de la "comunidad" puede ocurrir que varias edades estén juntas.

La Coordinación también se encarga de "supervisar" las actividades que propongan los madrijim y madrijot y orientarlos en las dudas que se les presenten. Usualmente, el coordinador o la coordinadora ya no están al frente de las actividades dirigidas a niños, niñas y adolescentes, sino que su contacto pasa por los madrijim y madrijot. En algunas "comunidades" se encuentra la Coordinación Educativa (rosh jinuj) encargada de pensar proyectos y recabar material didáctico para usarlo.

Por su parte, el director o directora y el profesor o profesora del "curso de madrijim" se ocupan de organizar y dictar las clases para los aspirantes. Siguen un programa con materias prefijadas pero a la vez pueden incorporar contenidos que consideren pertinentes trabajar, según el diagnóstico que se haga del grupo. Puede notarse esa doble dinámica donde se abordan contenidos preestablecidos y otros que pueden ser sugeridos por el profesor o profesora del curso. La formación se crea y se recrea en la interacción. Por más que se aprehenda el mundo en términos reificados, los actores lo siguen produciendo y resignificando (Berger y Luckmann, 2015).

Esta lógica se replica en la labor cotidiana de los madrijim y madrijot. Éstos serán los encargados de llevar adelante las actividades los días sábados y de tener un contacto directo con los educandos y educandas (janijim y janijot).Las y los educandos de "Jardín" y "Primaria" tienen actividad por la tarde mientras que las y los de "Secundaria" la tienen por la tarde-noche. Según el proyecto planteado las y los líderes deberán "bajarlo" de acuerdo con los intereses y/o problemá- 
ticas propias del grupo asignado y preparar una "planificación" con un subtema elegido que derivará del tema general. La planificación incluye objetivos, las actividades y materiales para alcanzarlos. Suelen trabajan en duplas. Deben pensar actividades generales dirigidas a todos los educandos y educandas, actividades para todos los chicos y chicas de una misma área y para cada grupo en particular. Al mismo tiempo, son los encargados de comunicarse semanalmente con los chicos y sus familias, ya sea por teléfono o en menor medida en forma virtual para informar sobre la propuesta del fin de semana o algún evento especial en que se requiera una mayor anticipación. Por ejemplo, un bingo, un baile o los emblemáticos campamentos o majanot. Las llamadas telefónicas cobran centralidad a la hora de comunicarse.

Los madrijim y las madrijot aprovechan ese espacio también para fortalecer vínculos con sus educandos y educandas, generar cercanía y confianza; además, los primeros tienen una relación próxima con los padres. Se prioriza la comunicación cara a cara. En este tipo de relación puede observarse cómo entra en juego el vínculo comunitario. Se establecen lazos de amistad en el marco de una organización específica. Se podría decir que esta interacción entre emprendedores y familias está dada en los marcos institucionales y no fuera de ellos.

"Hice una dinámica que era que cada vez que los llamo en la semana me tienen que decir una cosa especial que les haya pasado en la semana que sea diferente a las pasadas. Y ya el contacto con el chico es mucho más que quizás verlo en lapeulá (actividad). O sea, ya te dice todo el reflejo de su semana al verlo en la peulá (actividad)" (Entrevista a Tali, madrijá de Comunidad Menorá, 18 años, 27 de abril de 2017).

"Yo tengo que hacer llamados para los janijim y me da con la facultad. Iba en el colectivo llamando a los padres porque salgo de la facultad a las ocho de la noche y ya es tarde para llamar. No me da. Me la rebusqué este año. Hice un grupo de Whatsapp con los papás e hice otras cosas pero siempre no es lo mismo que el llamado y el estar presente desde ese lado" (Entrevista a Jésica, madrijá de Comunidad Menorá, 20 años, 24 de enero de 2017).

Ser madrij/a implica poner el cuerpo, estar presente en la "comunidad". Además de los llamados, planificar una actividad, supervisarla con el coordinador o coordinadora, preparar los materiales y luego ejecutarla, también asisten a una reunión semanal con todo el tzevet (el grupo que incluye a todos los emprendedores y emprendedoras) donde organizan las actividades generales o por área. Se les recomienda a las y los madrijim asistir a la sinagoga los días viernes para el servicio de Shabat e ir a las capacitaciones que la Dirección considere relevante. 


\section{El contenido judio, Ethos y valores}

Los temas que se desarrollan en las actividades suelen ser variados: problemáticas concretas del grupo, su desarrollo cognitivo, fechas patrias, la Shoá, conflicto árabe-israelí y aquellas con contenido judío. Las y los emprendedores suelen trabajar a éstas últimas desde las festividades donde se busca transmitir las costumbres, los símbolos, el contexto histórico en el que está basada alguna leyenda. Buscan recuperar algún valor de las mismas y mostrarles a los educandos y educandas que dichos relatos son aplicables a la actualidad. Las festividades, los símbolos y las costumbres son los dispositivos que permiten construir en las ylos emprendedores y en las y los educandos un ethos.

"Pesaj también depende la edad. Hay veces que con los nenes chiquitos es más fácil trabajar, es más importante trabajar qué es la keará7, qué pasó, la historia. Yo tenía a los más grandes y también trabajé la historia porque junto algunos no estaban enganchados con qué es lo que había pasado y después distintos valores, que se yo. Por ejemplo trato la esclavitud. La esclavitud desde ahora (...) que en Argentina siguen habiendo esclavos. Ese tipo de cosas. Ver que no todo es muy lejano" (Entrevista a Irina, madrijá de Comunidad Nefesh, 19 años, 1 de mayo de 2017).

"Desarrollaron el sentido de las palabras, que ellas tienen valor y un peso y que muchas veces pueden lastimar a otros. Que uno puede putear, que ellos como madrijim lo hacen pero que hay ámbitos para hacerlo. Luego relacionaban este tema con la "Torre de Babel", historia que contaba que todos los individuos hablaban diferentes idiomas y nadie se entendía. Con ello, se buscaba rescatar la importancia de la comunicación y el respeto. Que los chicos al ser pequeños, les cuesta expresarse con las palabras y que ante un problema lloran, entonces ellos como madrïim buscaban que puedan hablar, comunicar lo que les pasa” (Notas de campo, entrevista a Nicole, madrijá de Comunidad Menorá, 17 años, 14 de diciembre 2016).

Como se observa en los testimonios, se retoman fragmentos bíblicos como disparadores que interpelan a las y los educandos con problemáticas cotidianas o con su etapa de crecimiento. El acento está puesto en que además de transmitir un mensaje o valor, se acerquen a las historias del pueblo judío. Aparece el recurso del rol-playing y el uso del cuerpo para recrear los momentos. Las y los

7. Bandeja pascual compuesta por diferentes alimentos que representan los distintos momentos del relato bíblico. 
emprendedores daban distintos ejemplos. Recrearon la vida del Pueblo de Israel en el desierto tras la salida de Egipto. Los educandos y educandas debían dividirse y representar las tribus de Israel, armar sus propios símbolos, canciones, etc. Otro emprendedor contó que hicieron distintos juegos tomando la historia de Abraham para que además de lograr que los educandos y educandas se familiarizaran con el relato bíblico, pudieran acercarse al personaje. El patriarca había abandonado su mundo conocido, había salido de su "zona de confort" debido a su fe. Se rescataba la idea de cambiar y de no temer a los cambios.

"La historia de Abraham es también muy interesante porque él trabajaba con su papá haciendo esculturas de diferentes dioses, hasta que se comunicó con Dios y tomó otro camino Abraham. Y bueno, qué difícil es dejar su vida que tenía y armar una vida totalmente distinta a la que tenía (...) es esto de cambiar, salir de la zona de confort. Abraham estaba ahí con su papá en la casa haciendo sus esculturas y dejó todo. Agarró otro camino totalmente distinto...” (Entrevista a Guido, madrij de Comunidad Tefilá, 20 años, 13 de julio de 2017).

La transmisión de valores tales como fomentar la unión, la pertenencia, la inclusión del otro y la buena convivencia, es algo que resulta ser una "convención” (Douglas, 1996) entre las y los jóvenes emprendedores. Se abordan las problemáticas de grupo y se resalta la importancia de que todos participen tanto en las actividades semanales como en los eventos especiales y en los campamentos. En la mayoría de los relatos de los y las jóvenes aparece la importancia de los bingos, los "café concert", los "shows de bandas" comunitarios anteriormente nombrados para recaudar fondos para las becas para los campamentos de invierno y de verano de manera que todos los educandos y educandas asistan. La participación y la presencia del grupo en su conjunto también son consideradas valores. Se espera que otros departamentos de la organización (Comisión Directiva, Voluntarios, Comisión de Padres, etc.) cooperen y participen de la propuesta. Se establece un sistema de reciprocidades donde todos deben participar en todo no solo en pos del objetivo puntual sino por la "comunidad" en sí.

\section{Motivaciones}

Las motivaciones que los y las jóvenes tienen para hacerlo, son múltiples. Las respuestas más nombradas fueron aquellas relacionadas con un mandato comunitario. Existe una empresa a largo plazo que los trasciende y los involucra (Tilly, 2010). Está presente en los relatos de las y los entrevistados la idea de un 
sistema de "prestaciones totales". Una frase muy común en ellos es "devolver lo que me dieron a mí”. Remarcan que allí conocieron a sus amigos, tuvieron un marco de pertenencia y de contención de la organización y que por eso sienten un fuerte compromiso y una necesidad de retribuir. En este intercambio de prestaciones y contraprestaciones entre los y las jóvenes y la "comunidad”, los primeros para seguir dentro de ella deciden participar voluntariamente aunque en el fondo sea obligatorio, pues si no es de esa manera quedan fuera de la misma.

"Yo siempre dije que quiero ser madrijá para devolver lo que me dieron a mí. Todos los años hermosos y la gente que conocí y a todos mis amigos. Yo también quiero que mis janijim tengan todo eso, yo también quiero ser madrijä" (Entrevista a Cynthia, madrijá de Comunidad Nefesh, 18 años, 10 de febrero de 2016).

Asimismo, otra razón para ejercer este trabajo voluntario es el poder transmitir los valores, las enseñanzas y las costumbres judías a través de la educación no formal. Esta última resulta constitutiva al definir lo qué son y lo qué hacen y es eso lo que más los vincula con lo masortí. Se puede notar cómo los y las jóvenes toman justificaciones que responden a una "lógica racional con arreglo a valores"(Weber, 1964) para identificarse con un movimiento religioso. Encuentran en la educación no formal un medio para ayudar al otro. Tuvieron experiencias solidarias previas que los motivaron a tomar esa decisión.

Pero también resulta ser una instancia de sociabilidad dentro de un repertorio de ofertas para estos jóvenes judíos. Hacen hincapié en el hecho de conservar las amistades o incluso en la posibilidad de hacer nuevas y de tener un espacio recreativo los fines de semana.

"Hay varios que le gusta ser madrij para dar contenido, juegos, liberarse, poder tocar la parte humanística de tu vida, no me interesa tanto. Me interesa más estar en Comunidad Menorá para mantener los lazos y amistades que tuve toda la vida. Yo si no voy a Comunidad Menorá, pierdo esos lazos. Me gusta estar acá. Después, le encuentro el gustito de ser madrij pero no es lo principal para mí" (Entrevista a Federico, madrij de Comunidad Menorá, 19 años, 9 de enero de 2017).

\footnotetext{
8. Si bien Marcel Mauss (2009) utiliza este concepto para hablar del intercambio de bienes entre clanes, familias y tribus, también puede aplicarse a nuestro objeto de estudio. El sistema de prestaciones totales es un tipo de institución que incluye prestaciones y contraprestaciones de riqueza de diferente tipo (fiestas, ritos, danzas, colaboración militar, etc.) que sostienen un contrato general y permanente entre las partes. "Estas prestaciones y contraprestaciones se realizan de forma más bien voluntaria, a través de presentes o regalos, aunque en el fondo sean rigurosamente obligatorias, a riesgo de desatarse una guerra privada o pública" (Mauss, 2009, p. 75).
} 
En otros casos, decidieron participar de este modo porque una figura los marcó ya sea un referente comunitario o un madrij o madrijá, cuando ellos eran educandos o educandas. Hubo una figura carismática, que resultó ser un modelo a seguir, que los incentivó y confió en ellos. En este sentido, las motivaciones de las y los emprendedores estuvieron dadas por una "acción afectiva". Destacan que ese vínculo de cariño y contención incidió en esa decisión. Igualmente, recalcan que les gusta el trato con los niños, niñas y adolescentes. Esto se ve implicado en su vocación profesional; así, 16 casos estudian una carrera de grado o terciara relacionada con la educación y/o docencia. Incluso ocurre que estén estudiando una determinada carrera y en forma paralela estén haciendo el "curso de morim" ${ }^{10}$ en el Seminario Rabínico Latinoamericano.

Salvo algunas excepciones, el joven que decide abandonar el Departamento de Juventud no tiene una posibilidad de inserción. Las "comunidades" no ofrecen propuestas para ese nicho de jóvenes. Pueden participar asistiendo a los servicios religiosos o buscando alguna tarea específica para colaborar como voluntario de alguna manera. En este punto se pone en juego la tensión pasión-razón. En primera instancia, las y los emprendedores no sienten conflictos con que dicha labor sea voluntaria y escasamente remunerada. Por el contrario, lo ven como un valor adicional ya que al hacerlo por gusto, no hay un techo o especulaciones respecto de cuánto hacer o no. Su motivación está puesta en contribuir con la "comunidad", en "devolver lo recibido". Sin embargo, las "acciones racionales con arreglo a fines" ${ }^{11}$ suelen ser una de las causas más nombradas de por qué estos jóvenes dejan de ejercer el "madrijato" ${ }^{12}$. La necesidad de trabajar, de percibir un sueldo junto con otras responsabilidades hace que el tiempo que se le destine a este trabajo voluntario sea cada vez menor al punto tal de abandonarlo.

\section{Juventudes en el movimiento masortí: tensiones con el mundo adulto}

Los y las jóvenes dan cuenta de la existencia de consumos culturales judíos y que la propuesta comunitaria es atractiva en momentos de crisis económicas por ser una opción de bajo costo; sin embargo, ellos enfatizan que la fortaleza de su propuesta responde al hecho de enseñar un modo de habitar comunitario.

\footnotetext{
9. "especialmente emotiva, determinada por afectos y estados sentimentales actuales" (Weber, 1964, p. 20).

10. Curso para aspirantes a ser maestros de hebreo para dar clases en escuelas tanto en nivel primario como medio.
}

11. "determinada por expectativas en el comportamiento tanto de objetos del mundo exterior como de otros hombres, y utilizando esas expectativas como "condiciones" o "medios" para el logro de fines propios racionalmente sopesados y perseguidos" (Weber, 1964: 20) [La itálica es del texto original].

12. Categoría nativa que utilizan para referirse al ejercicio de ser madrij. 
No solo se aprende un conjunto de valores, tradiciones y leyes sino que resulta ser un espacio de pertenencia que involucra a otros y concientiza sobre la continuidad. Que el trabajo voluntario de las y los emprendedores sea escasamente remunerado también contribuye a ese ethos comunitario. El dinero, la percepción de un sueldo o pensar este trabajo de un modo profesionalizado resulta conflictivo en los y las jóvenes. Coincidiendo con Sebastián Fuentes (2018) en este universo juvenil también existe una tensión entre la moralidad y el dinero. Los y las jóvenes incorporaron esta “convención” (Douglas, 1996) para pensar su rol de emprendedores siendo un trabajo que no se puede cuantificar monetariamente. Incluso, que sea así le da un valor adicional que los diferencia de “otros”. Se lo realiza porque la principal motivación es la de seguir fortaleciendo los lazos de pertenencia.

E:- "El trabajo que vos hacés es voluntario...

L:- Es voluntario, tenemos un salario de $\$ 360$. Claramente es voluntario. Un madrij no lo hace por la plata. Tuve, la semana pasada no, la anterior tuve una suplencia en $C l u b X X X^{13}$ y tuve ese debate. Hay gente que no lo hace voluntariamente porque en los clubes te pagan una "luca" por mes o depende tu antigüedad $\$ 1500$, \$2000. Pero me parece que uno no es madrij por la plata y si lo hacés por la plata perdoname pero sos un boludo.

E:- Para vos está bueno que sea así.

L:- Claro, sí. Es un poco el devolver a tu comunidad o a tu club lo que te dejaron y me parece que eso no se paga con plata. Eso se paga también con sonrisas, se paga con un "gracias" de los chicos, se paga con los padres que vienen y te dicen "Gracias por esta peulá (actividad) que estuvo tan linda". Pero no porque te pongan un "Roca" ${ }^{14}$ sobre la mano. No es la forma de agradecer, o sea. Si me querés pagar, bárbaro, hacelo. Estás ahorrando, buenísimo, pero no es la única forma, me parece" (Entrevista a Lara, madrijá de Comunidad Le Olam, 19 años, 8 de agosto de 2017$)$.

De la misma manera, entienden que más allá del vínculo emocional que tienen con la organización y con sus amigos, agradecen que dicho rol les brindara experiencia para desenvolverse en futuros trabajos por haber adquirido

13. Club judío con sedes en la Ciudad Autónoma de Buenos Aires y en el Conurbano Bonaerense.

14. Hace alusión al billete de 100 pesos argentinos que lleva la figura de Julio Argentino Roca. 
responsabilidades, habilidades pedagógicas, coordinar grupos, comunicarse con el mundo adulto, etc.

El dilema está en que esta es la forma institucionalizada que encuentra el movimiento masortí en sus "comunidades" para hacer partícipe al joven. Está pensando en una juventud específica que debe "activar" haciendo un trabajo voluntario, lo que implica que luego de haberlo realizado por dos o tres años aparece en ella el cansancio, la decepción, el hartazgo, la presión porque no deja de ser un trabajo exigente, que demanda mucho tiempo. Los y las jóvenes deben balancear sus rutinas tratando de cumplir con sus otras obligaciones (estudio, trabajo, etc.) al punto tal de abandonarlo, sabiendo que momentáneamente no tendrán otro espacio de inserción. Reclamar que sea un trabajo profesionalizado para continuar participando atenta con la idea de mandato comunitario, pero seguir sosteniéndolo bajo estas condiciones implica en el corto o mediano plazo dejar la "comunidad". En un punto, el rol de emprendedor pone a los y las jóvenes en un lugar de vulnerabilidad y precarización. Las expectativas respecto de cuánto tiempo hacerlo es cada vez menor. Llevar adelante este trabajo junto con las obligaciones extra-comunitarias en un momento les resulta incompatible.

D:- "Porque cada vez los momentos son más cortos. El madrij cuatro años ni en pedo dura. Como que antes vos querías ser director. Hoy hay menos que quieran. Hoy en el tercer año, el madrij tiene al grupo más grande y listo, se va, se quiere ir, me voy.

E:- ¿Hay una proyección de tiempo de cuánto uno quiere ser madrij?

D:- Se bajó el promedio (...) Hoy en el mundo, los estudios tienen una jerarquía, una presión que no tenían antes. Todos te dicen “iAy! iQué apuro tenés!". No tenés ningún apuro pero todos se quieren recibir. ¿Quién pone la vara? ¿Nadie tiene apuro o todos se quieren recibir? Todos nos queremos recibir. Si todos nos queremos recibir, la hadrajá (la educación no formal) te saca tiempo. ¿Para qué ser madrij si te tratan como el orto? ¿Qué me dan? No puedo trabajar y ser madrij. Soy madrij o trabajo. Bueno, listo, dos años, ya probé, gracias" (Entrevista a Diego, madrij de Comunidad Le Olam, 22 años, 28 de septiembre de 2017).

Dentro del movimiento masortí existen juventudes: aquellas que están institucionalizada a través de la educación no formal y las que no. En estas últimas, como ya se explicó, los y las jóvenes estudian algún terciario o alguna carrera de grado. O son profesionales o comerciantes. Trabajan, viven solos o están por dar ese paso y no tienen hijos. Muchas "comunidades" los definen como "los jóvenes 
universitarios” o según rangos etarios “jóvenes de 25 a 35 años” o “jóvenes de 20 a 35 ”. En el plano discursivo el mundo adulto está preocupado por garantizar su continuidad aunque en la práctica no ofrezca espacios ni radios de acción concretos (en algunas "comunidades" hay ciertos proyectos y actividades que se están desarrollando incipientemente).

Existen pautas de entradas y salidas. Se supone que el joven que deja de participar en la "comunidad" por medio del trabajo voluntario volverá, siendo padre o madre cuando tenga que elegir una educación y un espacio religioso para sus hijos. En este sentido, pueden observarse cambios generacionales. Aproximadamente hace 30 años atrás, el regreso a la "comunidad" era más inmediato porque la paternidad y la maternidad se resolvían a los veinte. Es decir que para ese contexto, efectivamente ser madrï o madrijá implicaba un rito de pasaje más inmediato a la adultez. Hoy pueden pasar 10 años hasta que ese joven que se fue, devenga en "adulto" y vuelva porque ya es padre o madre y quiera que sus hijos se formen en esa organización ${ }^{15}$.

Como en el testimonio anterior, los y las jóvenes expresan que sus experiencias difieren con generaciones anteriores. En algunos casos, sus padres que durante su juventud fueron madrijim o madrijot o hicieron un trabajo voluntario por períodos más prolongados ${ }^{16}$, manifiestan que los tiempos cambiaron, que todo es más vertiginoso y exigente, pero los jóvenes deben resolver en el plazo más corto posible su formación profesional y su inserción laboral. Ejercer la educación no formal o hacer planes de formación propuestos por el movimiento que implican una estadía de un año en Israel, en un punto entorpece estos objetivos. Más allá de los cambios estructurales, entienden que en la cultura argentina no se valora este tipo de proyectos ya que se espera que inmediatamente terminados los estudios secundarios, se enfocaran en la vida adulta. Aclaran que esto es un fenómeno local que difiere con otras partes del mundo. Por lo tanto, puede verse que el mundo adulto valora que sus hijos lleven adelante la educación no formal, pero por un período corto.

Aunque el mundo adulto está preocupado por los y las jóvenes que no regresan a las "comunidades", entienden que esta juventud a diferencia de la insti-

\footnotetext{
15. Tomando el estado del arte de Analía Otero (2010) existen teorías que explican estos cambios en los procesos de transición a la vida adulta en la 'modernidad líquida' (Bauman, 2009) que dejaron de ser lineales y previsibles. Podemos encontrar 'las biografías de elección' es decir, trayectorias juveniles que no solo tienen en cuenta la formación académica sino también sus deseos y decisiones (Du-Bois, 1998); y aquellas vinculadas con 'nuevos modelos de la vulnerabilidad' (Furlong y Cartmel, 1997; Wyn y Dwyer, 2000).
}

16. Un emprendedor contaba que su madre participó en la hadrajá (educación no formal) ejerciendo diferentes puestos por 10 años. Otro decía que dada la vasta experiencia que su madre había tenido en la educación no formal cuyo principal puesto alcanzado fue el de directora hizo que eligiera dicho espacio de socialización para sus hijos. 
tucionalizada en caso de participar no lo haría de acuerdo con la idea de mandato comunitario sino por razones utilitarias.

"Ser judío es caro. Lo sabemos, lo saben nuestros bolsillos y nuestros presupuestos y esto se debe en parte a algo que a mí me gusta llamar "el efecto Bria" o "el efecto Birthright". Birthright ${ }^{17}$ es un programa fantástico que ha llevado a cientos de miles de jóvenes a Israel impactando en sus vidas e impactando en las comunidades judías del mundo pero ha dejado una marca profunda en esos jóvenes que dicen “yo no voy a pagar para ser judío. Ustedes me pagan a mí para que sea judío”. La gratuidad es esperada. Tenemos que, un gran desafío es cambiar ese paradigma. Cambiar el paradigma de si vos pagás para ir al cine por qué no para un curso si ambos son qualitytype" (Discurso del rabino Damián A. en el "Encuentro Anual Seminario”, Buenos Aires, mayo de 2017).

Este testimonio percibe nuevas formas de participación en el mundo judío: existen organizaciones que ofrecen actividades financiadas por ellas mismas para convocar a jóvenes por medio de propuestas atractivas, nuevos espacios de socialización. Las motivaciones en asistir podrían estar dadas por querer generar un vínculo de pertenencia y en comprometerse en una empresa a largo plazo como sí sucede en las “comunidades” masortí o por la propuesta en sí misma sin importar posicionamientos ideológicos o la corriente religiosa. El que se acerca al espacio no lo hace únicamente en carácter de feligrés sino también como consumidor de una oferta concreta.

Las y los emprendedores cuentan que participaron o están participando en cursos de estudios de organizaciones ortodoxas para hacer un viaje a Israel o a Nueva York. De acuerdo con la cantidad de clases asistidas, el costo baja. Sus motivaciones están dadas por la posibilidad de hacer un viaje, oferta que les resulta atractiva y que sería sumamente difícil de pagar por sus propios medios, y para hacer amistades o encontrar pareja. Aquellos que ya lo habían hecho dejaron de tener contacto con dichas organizaciones, siguiendo participando en su "comunidad” masortí. En el caso de los y las jóvenes no institucionalizados expresaban haber participado de esas propuestas. En algunos casos, luego de haberlas hecho seguían vinculadas con ellas por sentirse cómodos, por haber armado vínculos de afecto con pares y con rabinos o por estar interesados en sus propuestas.

A la vez, existe una mirada estereotipada sobre el joven. El rabino entiende que existe una juventud que participa evaluando costos y beneficios, desestimando una realidad: el movimiento conservador/masortí no ofrece espacios

17. Programa educativo de diez días de muy bajo costo dirigido a jóvenes judíos entre 18 y 26 años para visitar y recorrer Israel. Deben tener ascendencia judía ya sea de padre o madre. 
para todas las juventudes. El mundo adulto del movimiento masortí concibe que el joven que participa lo hace a partir de una “acción racional por arreglo a valores" que contrasta con otros jóvenes no institucionalizados que de hacerlo sería en pos de buscar un beneficio vinculado con una 'acción racional con arreglo a fines'. En el caso del movimiento conservador/masortí, el dinero o el hecho de participar de una actividad de modo pasivo en busca de un beneficio concreto romperían con los valores de ethos comunitario.

\section{Conclusiones}

Esta investigación busca hacer un aporte al campo de las ciencias sociales en general y a la sociología de la religión en particular ya que repone en una de las temáticas centrales: la constitución y reproducción del lazo social, o dicho con otras palabras, las tensiones que acompañan la apuesta de los grupos comunitarios por reproducirse en espacio y tiempo, frente a los desafíos que proponen las formas de individuación contemporánea.

El movimiento masortí ofrece espacios de socialización para una juventud institucionalizada y para las familias.La juventud institucionalizada habita lo comunitario por medio de un rol específico en pos de una empresa a largo plazo que la involucra y la trasciende. Es esa condición de juventud específica, ese proceso de transición en el que gozan de un permiso de menor exigencia a la vida adulta (Margulis y Urresti, 2008), la que posibilita que pueda habitar ese espacio comunitario de ese modo y, por lo tanto, desarrollar ese ethos, que flaquea cuando dicha condición de juventud cambia en la medida que las exigencias profesionales y laborales son mayores y los espacios de inserción comunitaria se acotan.

La juventud no institucionalizada, la que ya no participa en los Departamentos de Juventud ni tiene hijos, no cuenta con espacios concretos. Circula por diferentes ámbitos judíos o no, seculares o religiosos para hacer amistades, buscar pareja o vivir experiencias atractivas, estableciendo diferentes modos de identificación.

El mundo adulto está preocupado por su continuidad ya que su regreso no está garantizado. No solo debe hacer frente a las transformaciones generacionales sino también a aquellas relacionadas con la pluralización del campo religioso judío que habilita nuevos modos de habitar. Cuestionan esta falta de fidelidad institucional pero a la vez son conscientes que las "comunidades" no logran sostener ofertas que perduren en el tiempo por falta de recursos humanos o económicos que las financien y sostengan. Esperan que todo lo vivido en su infancia y adolescencia los motive a regresar. 


\section{Referencias}

Alvarado, S.; Vommaro, P. (2010). (Comp.). Jóvenes, cultura y política en América latina: Algunos trayectos de sus relaciones, experiencias y lecturas (1960-2000). Homo Sapiens Ediciones.

Aviad, J. (1983). Return to Judaism. Religious Renewal in Israel. The University of Chicago Press.

Barrón, E. (2018). Creencias y modos de abordaje en torno del suicidio juvenil. Universidad Nacional de la Matanza.

Baumann, G. (2001). El enigma multicultural: un replanteamiento de las identidades nacionales, étnicas y religiosas. Paidós.

Bauman, Z. (2008). Comunidad. En busca de seguridad en un mundo hostil. Siglo XXI.

Bauman, Z. (2009). La modernidad líquida. Fondo de Cultura Económica.

Becker, H. (2014). Outsiders: Hacia una sociología de la desviación. Siglo Veintiuno Editores.

Berger, P.; Luckmann, T. (2015).La construcción social de la realidad. Amorrortu.

Bianchi, S. (2004). Historia de las religiones en la Argentina. Las minorías religiosas. Sudamericana.

Bokser-Liwerant, J. (2011). Los judíos de América Latina. Los signos de las tendencias: Juegos y contrafuegos. En H. Avni, J. Bokser-Liwerant, S. Della-Pergola \& M. Bejarano (Comps.). Pertenencia y alteridad. Judíos en/ de América Latina: Cuarenta años de cambios (pp.115-164). Iberoamericana Vervuert.

Bourdieu, P. (1990). Sociología y Cultura. Grijalbo:

Bourdieu, P. (2006). Génesis y estructura del campo religioso. Relaciones. Estudios de historia y sociedad, 27(108), 29-83. El Colegio de Michoacán, A. C. Zamora. 
Brauner, S. (2009). Ortodoxia religiosa y pragmatismo político (los judíos de origen sirio). Lumiere.

Caro, I. (2006). Comunidades judías y surgimiento de nuevas identidades: el caso argentino. Atenea, 497, 79-93. https://scielo.conicyt.cl/pdf/atenea/n497/ art06.pdf

Chaves, M. (2010). Jóvenes, territorios y complicidades. Una antropología de la juventud urbana. Espacio.

Cohen, G. (1987). Conservative Judaism. En A. Cohen \& P. Mendes-Flohr (Eds.). Contemporary Jewish Religious Thought. Original essays on critical concepts, movements, and beliefs (pp. 91-99). Charles Scribner's Sons.

Cooper, A. (1989). No longer invisible: Gay and lesbian Jews build a movement. Journal of Homosexuality, 18(3-4), 83-94. https://europepmc.org/article/ $\mathrm{med} / 2696759$

Della-Pergola, S. (2011). ¿Cuántos somos hoy? Investigación y narrativa sobre población judía en América Latina. En H. Avni, J. Bokser Liwerant, S. Della-Pergola \& M. Bejarano (Comps.). Pertenencia y alteridad. Judíos en/ de América Latina: Cuarenta años de cambios (pp. 305-340). Iberoamericana Vervuert.

Denscombe, M. (1999). The Good Research Guide for Small-scale Social Research Projects. Open University Press.

Douglas, M. (1996). Cómo piensan las instituciones. Alianza Universidad.

Du-Bois, R. (1998). I Don't Want to Commit Myself Yet: Young People's Life Concepts. Journal of Youth Studies, 1(1), 63-79. https://www.tandfonline. com/doi/abs/10.1080/13676261.1998.10592995

Erdei, E. (2011). Demografía e identidad: a propósito del estudio de población judía en Buenos Aires. En H. Avni, J. Bokser-Liwerant, S. Della-Pergola \& M. Bejarano (Comps.). Pertenencia y alteridad. Judios en/de América Latina: Cuarenta años de cambios (pp. 341-364). Iberoamericana Vervuert. 
Fainstein, D. (1994). Identidad, comunidad y Halajá. Reflexiones en pos de un Judaísmo Masortí relevante y auténtico (Documento inédito). Consejo Intercomunitario Judaísmo Conservador.

Fainstein, D. (2006). Secularización, Profecía y Liberación: La desprivatización de la religión en el pensamiento judío contemporáneo. Un estudio comparativo de sociología histórica e historia intelectual (Tesis doctoral, inédita). Universidad Nacional Autónoma de México.

Feixa, C. (1998). De jóvenes, bandas y tribus (Antropología de la juventud). Ariel.

Fernández, N. S. (2018). Construcciones de juventud, prácticas democráticas y vínculos intergeneracionales en el escultismo católico contemporáneo de Argentina. Ánfora, 25(44), 177-203. https://publicaciones.autonoma.edu. co/index.php/anfora/article/view/461

Freire, P. (2005). Pedagogía del oprimido. Siglo XXI Editores.

Fuentes, S. (2018). Rugby, educación solidaria y riqueza en las elites de Buenos Aires: la construcción de una clase moral. Etnográfica, 22(1), 53-73. https://journals.openedition.org/etnografica/5147

Furlong, A.; Cartmel, F. (1997). Risk and Uncertainty in the Youth Transition. Young, 5(1), 3-20. https://journals.sagepub.com/ doi/10.1177/110330889700500102

Giménez-Béliveau, V. (2016). Católicos Militantes. Sujeto, comunidad e institución en la Argentina. Eudeba.

Gómez, G. (2017). Carreras identitarias. Un estudio socio-biográfico sobre la membresía de JAG (Judíos Argentinos Gays) (Tesis de maestría, inédita). Universidad de Buenos Aires, Argentina.

Hervieu-Léger, D. (2004). El peregrino y el convertido. La religión en movimiento. Ediciones del Helénico.

Hupert, P. (2014). Judaísmo Líquido. Multiculturalismo y judíos solitarios. Editorial Biblos. 
Kacowicz, A. (2011). Israel, las comunidades judías y América Latina en un escenario internacional cambiante. En H. Avni, J. Bokser-Liwerant, S. Della-Pergola \& M. Bejarano (Comps.). Pertenencia y alteridad. Judíos en/ de América Latina: Cuarenta años de cambios (pp. 251-270). Iberoamericana Vervuert.

Kriger, M. (2016). La tercera invención de la juventud. Dinámicas de la politización juvenil en tiempos de la reconstrucción del Estado-Nación. Grupo Editor Universitario.

Lago, L. (2018). La producción de los cuerpos juveniles en el evangelismo pentecostal. Prácticas, discursos y agencia. Question, 1(58), 1-17. https://perio.unlp.edu.ar/ojs/index.php/question/article/view/4593

Laikin-Elkin, J. (1986). The Argentine Jewish Community in Changing Times. Jewish Social Studies, 48(2), 175-182. https://www.jstor.org/ stable/4467330?seq=1

Mallimaci, F.; Giménez-Béliveau, V. (2007). Creencias e increencias en el Cono Sur de América. Entre la religiosidad difusa, la pluralización del campo religioso y las relaciones con lo público y lo político. CONICET, 44-63. https://www.redalyc.org/pdf/269/26950904.pdf

Mannheim, K. (1990). Le problème des générations. Nathan.

Margulis, M.; Urresti, M. (2008). La juventud es más que una palabra. En M. Margulis (Ed.). La juventud es más que una palabra (pp.13-30). Biblos.

Mauss, M. (2009). Ensayos sobre el don. Katz Editores.

Mekler, V. M. (1992). Juventud, educación y trabajo. CEAL.

Melamed, D. (2000). Los judios y el menemismo. Un reflejo de la sociedad argentina. Editorial Sudamericana.

Meyer, M. A. (1995). Adapting Judaism to the Modern Word. En Respondense to Modernity. A history of the Reform Movement in Judaism (pp.10-61). Wayne State University Press. 
Mosqueira, M. (2014). "Santa Rebeldía". Construcciones de juventud en comunidades pentecostales del Area Metropolitana de Buenos Aires (Tesis doctoral, inédita). Universidad de Buenos Aires, Argentina.

Otero, A. (2010). Los avatares de la transición a la vida adulta, el papel de la educación y el trabajo en los recorridos juveniles. Revista Margen, 59, 1-13. http://www.margen.org/suscri/margen59/oter.pdf

Pérez-Islas, J. (2000). Jóvenes e instituciones en México. 1994-2000. SEP-Instituto Mexicano de la Juventud.

Redfield, R. (1971). The Little Community and Peasant Society and Culture. Chicago University Press.

Reguillo-Cruz, R. (2000). Emergencia de las culturas juveniles. Estrategias del desencanto. Norma.

Romero-Ocampo, J. (2010). Jóvenes y religión en un mundo de cambio. El caso de los jóvenes chilenos. Ciencias Sociales y Religión, 12(12), 147-156. http://cdsa.aacademica.org/000-062/1732.pdf

Rosemberg, D. (2010). Marshall Meyer el rabino que le vio la cara al diablo. Capital Intelectual.

Rubel, Y. (2011). La red educativa judía de la Argentina (1967-2007). En H. Avni, J. Bokser-Liwerant, S. Della-Pergola \& M. Bejarano (Comps.). Pertenencia y alteridad. Judíos en/de América Latina: Cuarenta años de cambios (pp. 529562). Iberoamericana Vervuert.

Sautú, R. (1999). El método biográfico: la reconstrucción de la sociedad a partir del testimonio de los actores. Belgrano.

Schenquer, L. (2012). Actitudes sociales en dictadura: Estudio sobre las dirigencias de DAIA y de las instituciones religiosas liberales durante el último régimen militar (1976-1983) (Tesis doctoral, inédita). Universidad de Buenos Aires, Buenos Aires.

Schutz, A. (1974). El problema de la realidad social. Amorrortu. 
Senkman, L. (2007). Ser judío en Argentina: las transformaciones de la identidad nacional. En P. Mendes-Flohr, Y. Assis \& L. Senkman (Eds.). Identidades judías, modernidad y globalización (403-454). Lilmod.

Setton, D. (2008). La dimensión emocional del "retorno a las fuentes" en el judaísmo ortodoxo. En F. Mallimaci (Comp.). Modernidad, Religión y Memoria (pp. 119-130). Colihue.

Setton, D. (2010). Judios ortodoxos y judios no afiliados en procesos de interacción: El caso de Jabad Lubavitch en la Argentina (Tesis doctoral, inédita). Universidad de Buenos Aires, Argentina.

Setton, D. (2014). Entre la sociabilidad y la politización: La construcción de lo judeo-homosexual-gay en Buenos Aires. Aposta, 62, 1-31. https://ri.conicet.gov.ar/handle/11336/2767

Setton, D. (2015). La construcción de identidades judías LGBT a través de prácticas diaspóricas: estudio sobre organizaciones judías LGBT en América Latina. Sexualidad, Saludy Sociedad, 21, 25-52. http:/ /www.scielo. $\mathrm{br} / \mathrm{pdf} / \mathrm{sess} / \mathrm{n} 21 / 1984-6487-\mathrm{sess}-21-00025 . \mathrm{pdf}$

Setton, D. (2020). La construcción simbólica de la geografía judeo-gay. En V. Giménez-Béliveau (Comp.). La religión ante los problemas sociales. Espiritualidad, podery sociabilidad en América Latina (pp. 317-338). CLACSO.

Sklare, M. (1972). Conservative Judaism. An American Religious Movenment. Schocken Books.

Tilly, C. (2010). Confianza y gobierno. Amorrortu.

Tönnies, F. (1979). Comunidad y asociación. Península.

Topel, M. (2005). Jerusalém e São Paulo: A nova ortodoxia judaica em cena. Topbooks.

Traverso, E. (2013). El final de la modernidad judia. Historia de un giro conservador. Fondo de Cultura Económica. 
Waxman, M. (1970). Tradition and Change. The Development of Conservative Judaism. The Burning Busch Press.

Weber, M. (1964). Economía y Sociedad. Fondo de Cultura Económica.

Weber, M. (1979). La ética protestante y el espíritu del capitalismo. Ediciones Península

Weil, A. (1988). Orígenes del movimiento judío conservador en la Argentina. Ediciones Seminario Rabínico Latinoamericano.

Weiss, A. (1988). The Decline and Rise of Jewish Life in Argentina 1970-1987. Princeton.

Wortman, A.(2001). Aproximaciones conceptualesy empíricaspara abordar identidades sociales juveniles y consumos culturales en la sociedad del ajuste. Documentos de Trabajo 24, 1-32 http://biblioteca.clacso.edu.ar/gsdl/collect/ar/ar-030/ index/assoc/D 154.dir/dt24.pdf

Wyn, J.; Dwyer, P. (2000). Nuevas pautas en la transición de la juventud en la educación. Revista Internacional de Ciencias Sociales, 164, UNESCO, 1729. http://www.unesco.org/new/fileadmin/MULTIMEDIA/HQ/SHS/ pdf/ 164-fulldocspa 164.pdf 
